\title{
Development of an Online Learning Management System (OLMS) a Case Study of Adamawa State University Mubi Nigeria
}

\author{
Isacha Habila \\ Department of Computer Science Adamawa State \\ University, Mubi Nigeria
}

\begin{abstract}
An Online Learning Management System or OLMS is a term used to describe web-based technology, designed to plan, implement, and assess a specific learning process. Online Learning Management System features can be viewed as comprising of four various tools which includes: a tool for distribution, a tool for communication, a tool for interaction and a tool for course administration. There is a dire need among ADSU students for a centralized learning system so as to enable them share learning materials, communicate, submit assignments and take assessments online, which has been implemented and adopted by many educational institutions but ADSU is yet to adopt the system. The software development methodology used to develop this system is the waterfall and the incremental model, the system is developed and implemented using Php, javascript, ajax, HTML and css. Online Learning Management System is designed, developed and implemented for ADSU Mubi using responsive design in order to encourage and facilitate learning through the use of internet and the available devices capable of accessing the internet regardless of the users' location. This work was not able to capture video content delivery and discussion forum. Therefore, it is open for further research so as to fill in these gaps.
\end{abstract}

\section{General Terms}

Learning Management System, E-learning.

\section{Keywords}

Learning, Learning Management System(LMS), Online Learning, Online Learning Management System(OLMS), ELearning.

\section{INTRODUCTION}

Learning management system is very essential to students and lecturers in this day and age, we can see clearly rapid changes and developments in technology (Cavus, 2009). Technological developments are forcing individuals, and consequently the institutions to become aware of the need to become part of the current era. It may also force them to reorganise themselves if necessary. Specially, a new era has started with the use of internet to access educational resources instantly. With the fast developments in the knowledge technologies, new methods have emerged in the generation of knowledge, the presentation of knowledge, and the way we reach the knowledge. Technological developments have also affected teachers' instructional techniques, with technology providing different perspectives to the concept of education (Uzunboylu, Bicen \& Cavus, 2011). Currently, internet has been preferred in education because of the technological possibilities it is providing, and its potential to reach much larger mass of people. The education system is perhaps at the top of the systems affected by technological changes, and is

\author{
Nathan Nachandiya \\ Department of Computer Science Adamawa State \\ University, Mubi Nigeria
}

undergoing fundamental changes. The learners are demanding more and more to learn at the time and place of their choice, and at their own learning speeds. The education technologies offer many advantages to students and teachers by helping them to learn using interactive and collaborative techniques (Concannon, Flynn \& Campbell, 2005). In particular, the internet nowadays is offering many tools and application packages to educators that can be used at all stages of teaching, and such tools increase the effectiveness and efficiency of teaching. Institutions use the LMS to supplement traditional face-to-face delivery where faculty members develop and share digital learning materials via the Internet. In this case, the LMS are used as an electronic repositories of learning materials (Vovides et al. 2007). Other institutions especially those offering distance education, have been combining LMS with traditional face-to-face delivery in order to reach more learners across various geographical boundaries (Andersson \& Grönlund 2009). Learning Management System is a software environment designed to manage user learning interventions as well as deliver learning content and resources to students. LMS can also refer to an application that is used for tracking, managing learning and administrating system, and is especially used in a learning environment. Therefore, Learning Management System should be able to provide learning contents, one-to-one interaction between Teachers and Students, passing announcements to students, Students assignments and organizing practice quiz questions; which in turn will enhance productivity and the utilization of internet especially in Adamawa State University, Mubi.

\section{LITERATURE REVIEW}

Learning Management Systems (LMS) are now installed in the majority of higher education institutions in sub-Saharan Africa. These web-based LMS are intended to support teaching and learning activities. They consist of various features that enable faculty members to share learning materials as well as providing interaction with their students both synchronously and asynchronously (Vovides et al. 2007). The most widely adopted LMS in the region are Blackboard, Sakai, KEWL, and Moodle (Unwin et al. 2010). Institutions use the LMS to supplement traditional face-to-face delivery where faculty members develop and share digital learning materials via the Internet. In this case, the LMS are used as an electronic repositories of learning. materials (Vovides et al. 2007). Other institutions especially those offering distance education, have been combining LMS with traditional face-toface delivery in order to reach more learners across various geographical boundaries (Andersson \& Grönlund 2009).

In light of these benefits, the adoption of LMS by higher education institutions in sub-Saharan Africa has continued to increase in recent years. Adkins (2013) predicted that LMS 
adoption will grow at the rate of $15 \%$ per annum between 2011 and 2016 in Africa. The increased adoption is further facilitated by the support of several international agencies such as the World Bank (WB), Swedish International Development Cooperation Agency (SIDA), United Nations Development Program (UNDP), African Development Bank Group (AfDB), and United States Agency for International Development (USAID) (Farrell \& Isaacs 2007). These agencies have been committing various resources to support institutions in adopting and implementing various LMS.

LMS have been successfully implemented in many institutions of developed countries. They have managed to improve students' learning performance, reduce students' dropout rates, and they have increased students' satisfaction with offered courses (Naveh et al. 2012). Institutions in subSaharan Africa have been adopting them in a bid to gain similar benefits as their counterparts elsewhere. However, the context of sub-Saharan Africa is different and institutions face different challenges from those faced by institutions in the developed countries. As a result, the adoption and implementation of these systems do not guarantee that institutions will enjoy similar benefits as those institutions in the developed countries.

Studies have also shown that there is a correlation between LMS usage and students' performance in courses offered via the LMS. For instance, Filippidi, Tselios, and Komis (2010) examined Moodle usage on students' performance at the University of Patras, Greece. It was revealed that LMS usage had a positive significant effect on students' performance, explaining $20.2 \%$ of variance in their total grade. These findings corroborate with another study conducted by Jo, Kim, and Yoon (2014) at the Ewha Womans University. The researchers found that regularity of LMS usage was a strong indicator on explaining learners' performance for the courses offered via the LMS.

Studies have also linked LMS usage with student satisfaction (Naveh et al. 2012). Increased LMS usage increases levels of students' satisfaction with courses. Similarly, satisfied learners tend to complain less (Tarigan 2011) and have possibilities of taking more courses (Booker \& Rebman 2005). According to Palmer and Holt (2009), satisfaction has positive correlation with quality of learning outcomes.

Nonetheless, simply saying that more usage will yield more benefits is insufficient (DeLone \& Mclean 2003). Delone and Mclean (2003) suggested that the nature, quality, and appropriateness of LMS use are important outcomes, and measuring time learners have spent on the system. Therefore, students need to use almost all features of the system in order to realize the expected benefit. For instance, Jo, Kim, and Yoon (2014) found that learners who more steadily log into the LMS from the beginning of a study to the end and used most of the LMS features showed better academic performance compared to others. In another study, students who used more LMS features such as assignment, forums, questionnaire and glossary were found to have better academic performance (Filippidi et al. 2010). Similarly, students who spent many days and many topic views had better learning results in courses offered via LMS at the Institute of Information Systems and New Media, Vienna University of Economics and Business (Mödritscher et al. 2013).

Therefore, the success of LMS in the region can be measured by assessing how these systems are used in terms of intensity and quality of use. In the next section, LMS adoption and usage in higher education institutions in sub-Saharan Africa is discussed in detail.

\subsection{LMS Adoption and Usage in Higher Education in Sub-Saharan Africa}

In recent years, there has been an increasing adoption of LMS in higher education in sub-Saharan Africa. Research conducted within the sub-Saharan Africa has also documented these LMS adoption patterns. Ssekakubo et al. (2011) found that five (5) of the surveyed institutions in sub-Saharan Africa had installed an LMS of various kinds. Similarly, Mtebe and Raisamo (2014) found half of 11 surveyed institutions had installed LMS while Munguatosha, Muyinda, and Lubega (2011) found that $80 \%$ of surveyed institutions in Tanzania were using LMS. Moreover, the seven institutions that participated in PHEA project were found to have installed various LMS (Hoosen \& Butcher 2012). Studies have also shown that several institutions have installed various LMS in countries such as Kenya, Mazambique (Unwin et al. 2010), Uganda (Mayoka \& Kyeyune 2012), Sudan (Elmahadi \& Osman 2013), and Zimbabwe (Chitanana et al. 2008).

Despite the increased adoption of LMS in the region, the actual usage is reported low. For instance, there were only 60 users in LMS installed at Makerere University in Uganda (Mayoka \& Kyeyune, 2012) and less than 10 users at Kenya's University of Nairobi (Ssekakubo et al. 2011). There were also 103 users at University of Dodoma, 767 users at the University of Dares Salaam, 81 users at Open University of Tanzania, and 49 users at Institute of Finance Management in Tanzania (Mtebe \& Raisamo 2014).

The situation is similar in several institutions in Zambia, Zimbabwe, Mozambique, and Sudan. For instance, only 20\% of trained users were using LMS at National University of Science and Technology of Zimbabwe (Dube \& Scott 2014). Studies have also revealed low usage of LMS at Maseno University in Kenya, Mondlane University in Mazambique (Unwin et al. 2010), University of Zambia (Ssekakubo et al. 2011), and in four leading universities in Zimbabwe (Chitanana et al.2008). Even those described as active and experienced users in institutions mentioned above, many of them use a relatively small number of the features (Unwin et al. 2010). Research has shown that communication tools that are embedded in LMS such as discussion forums, chat, and email are underutilized (Vovides et al. 2007). For instance, only $8 \%$ of users used communication tools of LMS at Open University of Tanzania (Bhalalusesa et al. 2013). It was also found that only $28 \%$ of users were contributing to discussions on the LMS at the University of South Africa (Venter et al. 2012).

Moreover, LMS have tools with capability to present the learning materials in various forms of multimedia such as audio, video and animations. Studies have shown that faculty members tend to underutilize such tools (Vovides et al. 2007). This is evident from the fact that the majority of faculty members at the National University of Science and Technology of Zimbabwe have been using LMS as a course information transmission tool only (Dube \& Scott 2014). Faculty members upload course information in text format for students to download just like any other electronic repository. The same situation was observed at the University of Dares Salaam in Tanzania in which 30 faculty members who indicated that they were using LMS, used the system for uploading content and files only (South Africa Institute of Distance Education 2013). Heeks (2002) pointed out that many information systems implemented in developing 
countries tend to fail partially or totally. The total failure is when the new system is implemented but immediately the system is abandoned. In many institutions in sub-Saharan Africa, users normally do not use the LMS after they have been trained. For instance, although more than 10,000 users were trained to use the LMS at the National University of Science and Technology of Zimbabwe only $20 \%$ continued to use it (Dube \& Scott 2014). This situation is almost similar in many institutions in the region.

The partial failure of information system is when the system is implemented but the major goals are not being attained (Heeks 2002). Improving the quality of teaching and learning, widening access to education, and reducing the cost of delivery are some of the motives behind LMS adoption. Given the low or non-use of LMS in the majority of institutions in higher education in sub-Saharan Africa, it is unlikely that the expected benefits of the systems is going to be realized. In the next section, strategies to increase LMS usage are discussed in detail.

\subsection{LMS in Nigerian Institutions}

Some of the institutions that uses LMS in Nigeria includes:

\section{- University of Jos (UniJos) LMS:}

This is an LMS wholly owned, operated and managed by the University of Jos. It allows for distance learning on a number of courses across most of their faculties

- Ladoke Akintola University of Technology (LAUTECH):

Learning Management Systems in LAUTECH provides a number of services for the enhancement of teaching and distant learning. It contains most of the components of modern LMSs.

Link: lms.lautech.edu.ng

- Tthe National Open University of Nigeria

The National Open University of Nigeria, NOUN, sprang from the ashes of the defunct National Open University, which was abruptly closed down by a military government in April 1984, barely one year after its establishment. In the year 2000, after an international workshop co-hosted by the Commonwealth of Learning, COL, and the Nigerian Federal Government, the years $2001-2010$ were declared a decade of open and distance learning in Nigeria.Thereafter, a time-line was drawn for series of activities and implementation strategies. One of such strategies was the resuscitation of the defunct open university which now had to be re-named National Open University of Nigeria (NOUN). It was clear in the mind of the planners right from the beginning that elearning or on-line learning would play a major role in the teaching and learning delivery system of the university.

\section{Objective of NOUN LMS.}

The main objective of the NOUN e-learning efforts is to encourage staff and students of the university to adopt an innovative approach to educational provisions and instructional deliveries. The design of the e-content was done in two ways. Some aspects were outsourced while others were developed internally by the university staff. E-content, was mainly in the form of text, audio, video and animation. Provisions were made for interactions, chats, assessment and evaluation, and also online counseling. Each aspect of the content was based on principles of self-learning.

\subsection{Improving Usability of LMS}

Usability is a measure of how users find the LMS easy to learn, easy to use, and user-friendly. This is an important aspect of LMS design as it has direct impact on how users use the system. If the LMS is easy to use and easy to learn, learners will use the system more often. On the other hand, the LMS which is perceived to be difficult to use, and is not user-friendly, learners spend more time learning how to use the system rather than learning the content (Ardito et al. 2005). In this case, users might feel lost, confused, or frustrated with the LMS (Tarigan 2011). Many institutions in sub-Saharan Africa have been adopting open source LMS (Unwin et al. 2010). However, the majority of open source systems suffer from usability problems (Nichols \& Twidale 2003). For example, Martin et al. (2008) found that no LMS reached $80 \%$ of compliance of usability heuristics in a study conducted to compare the usability of Moodle, Sakai, and dotLRN. Similarly, Moodle was found to have 75 usability problems in a study conducted to evaluate the usability of Moodle at FON University in Macedonia (Kakasevski et al. 2008). The authors also found that $80 \%$ of the students had significant problems with features of online chat and discussion forums.

Therefore, it is not clear whether the LMS are usable to learners in African institutions due to the fact that institutions have been implementing these systems without conducting usability evaluations (Ssekakubo et al. 2011). Since these systems were not developed specifically for African users, some usability problems must exist. For instance, $54 \%$ of interviewed Moodle users at the Open University of Tanzania indicated that the system was difficult to use especially in uploading learning materials (Bhalalusesa et al. 2013). Similarly, $84.4 \%$ of students and $79 \%$ of faculty members indicated that the LMS was not easy to use in a study conducted at Makerere University in Uganda (Mayoka \& Kyeyune 2012). In another study, Mabila, Gelderblom, and Ssemugabi (2014) found several usability problems that hindered students from using the LMS at the University of South Africa. The authors gathered evidence from heat maps and gaze plots using eye tracking evaluation method. Similarly, using heuristic evaluation inspection method Padayachee, Kotzé, and van der Merwe (2011) found that the LMS at the University of KwaZulu-Natal had several usability violations that made it difficult for many users to be able to use it. Generally, institutions should conduct usability evaluations to find out any usability problems that might be hindering users from using these systems. Fixing such usability problems will increase LMS usage due to the fact that many users will find the systems as easy to learn, easy to use and user-friendly. Thus, the system to be developed will be responsive and user-friendly to enhance the use of LMS in Adamawa State University.

\section{METHODOLOGY}

Study shows that ADSU has not yet adopted any Learning Management System. Due to this, it is important to note that ADSU needs the system to enhance learning and participation in the current technological trends.

The fact finding techniques used in order to study the existing system are: observation, interview and research.

Observation: This technique was used to obtain the overall structure of the existing system. This takes into consideration details pertaining to the various activities being carried out at the institution. Such activities include working condition, role of academic staffs and details and as well as students' attitude towards learning. 
Onsite observation was chosen because it enables me to practically see what is exactly happening and how everything is done within the existing system.

Interview: Using this method, students from some of the departments in ADSU were interviewed. Precisely students from Biological Sciences Department, Chemistry Department, Department of Accounting, Mathematics and Computer Science Departments. They welcomed the idea of Adopting LMS by ADSU Mubi which will enable them share learning resources, chat with their lecturers, download learning materials and access their profile from anywhere and at any time. According to a Student from Computer Science Department, LMS is very important to students as it saves time and resources and provides good and pleasing platform for learning.
Based on these responses, the researcher then finds it very important for ADSU to adopt LMS.

Research: Various academic journals were reviewed by the researcher which revealed the various components of learning management systems that has been on the use by many different academic institutions from around the world. The researcher then finds it interesting to see some standards of virtual learning are being integrated into the system.

\subsection{Software Development Methodology}

The software development methodology used for the development of this system is the Iterative Waterfall model and the Incremental model. Interactive Waterfall model provides system requirements to design software architecture to support these requirements and the incremental model supports development of a system as a series of versions each version with adding functionality to the previous version.

\subsection{System's Dataflow Diagram}

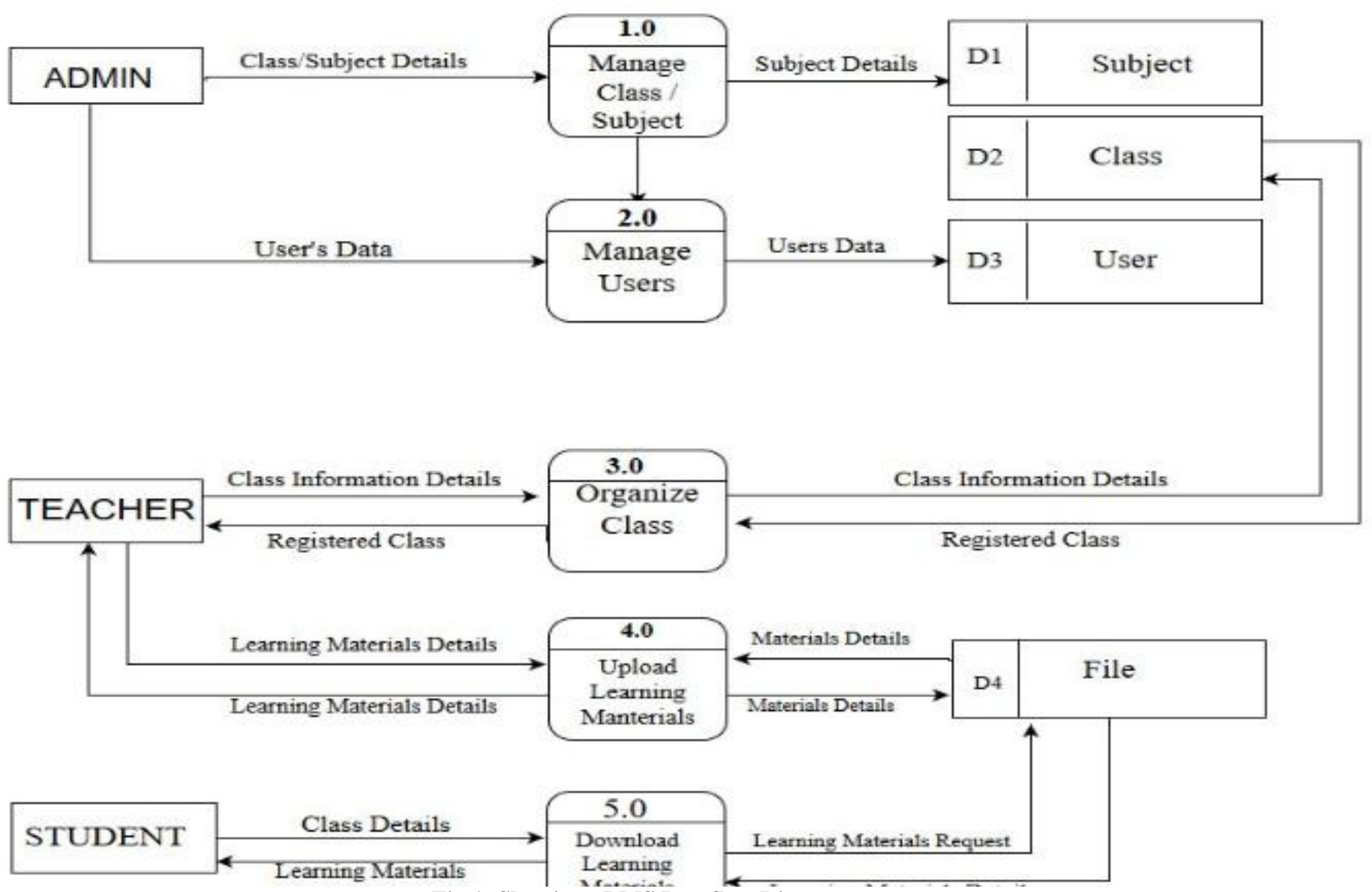

Fig 1: Showing LMS Dataflow Diagram

\section{RESULTS AND DISCUSSION}

This system allows only an administrator with valid credentials to $\log$ in to the system and manage the systems users, and content. The administrator registers every user; a student or a teacher has to be registered by the admin in order to allow him or her to sign Up and login to the system.

As shown below, a teacher after login, he or she can create his 


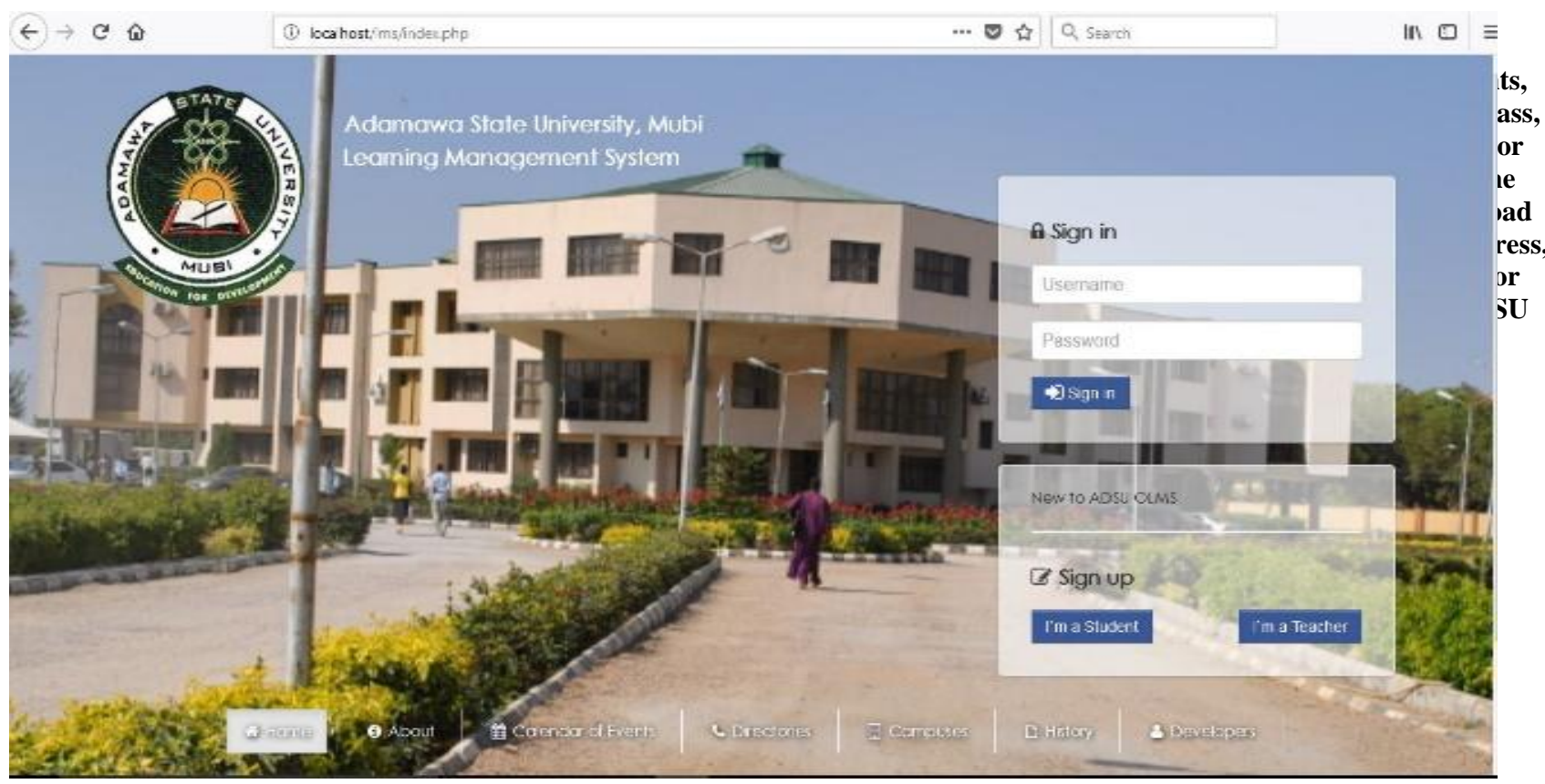

Fig 1: showing System Homepage, login and signup page

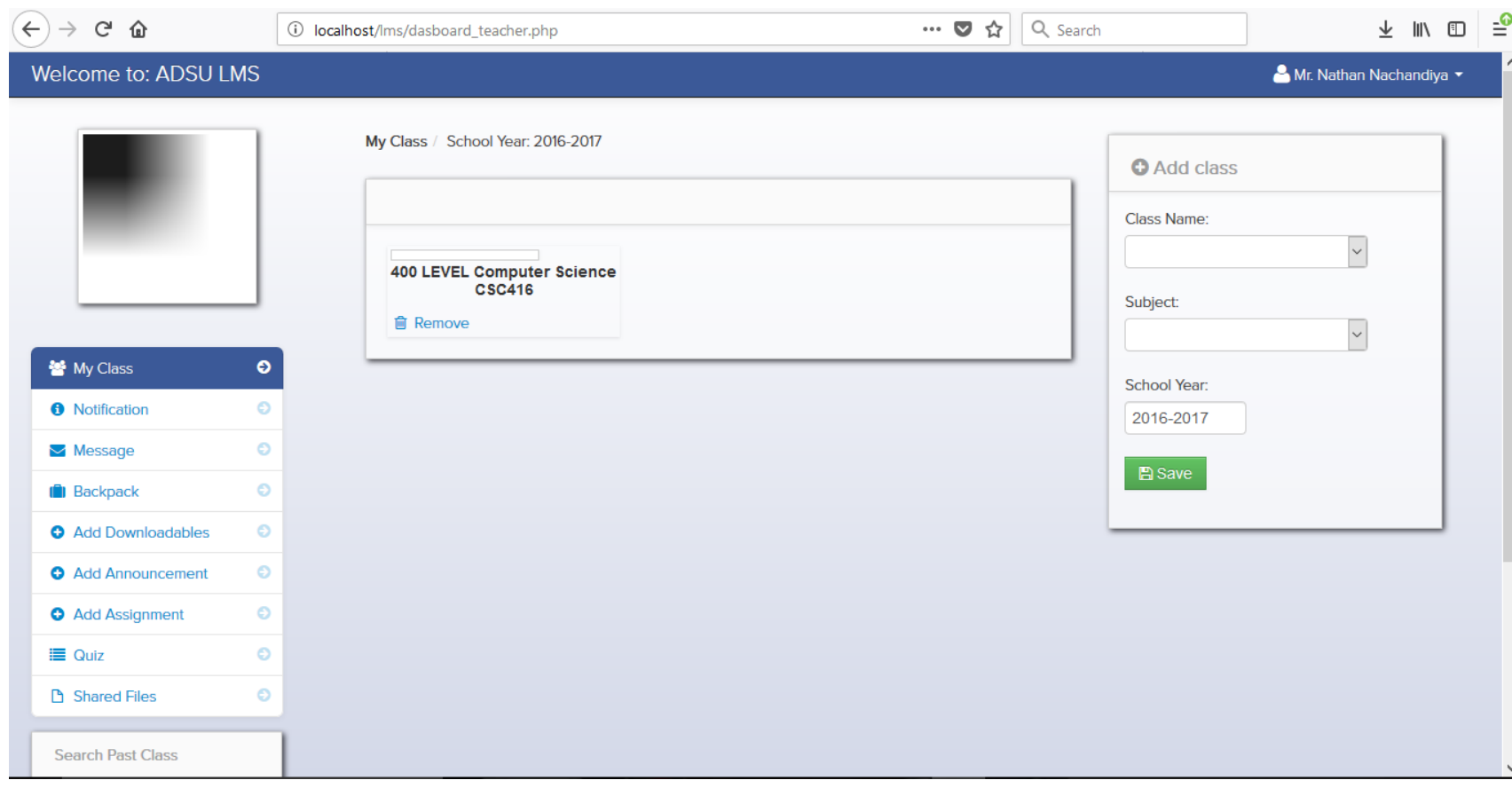

Fig 2. Showing teacher dashboard, list of students in class. 


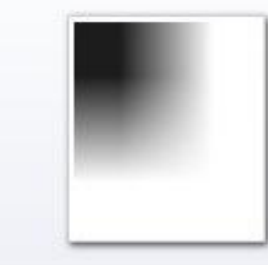

\section{$<$ Eack}

wh Sicents

3 Suace: Onervew

\section{(- Dawicadatle Materals $\Theta$}

E Assigments

(9) Arncuncements

界 Cass Colender

E $\mathrm{E}$ Cuik

Search Past Class

Schoa Year.
400 LEVEL Computer SdieneE / CSC416 SchoalYear.2016-2017 / Downibadable Materats

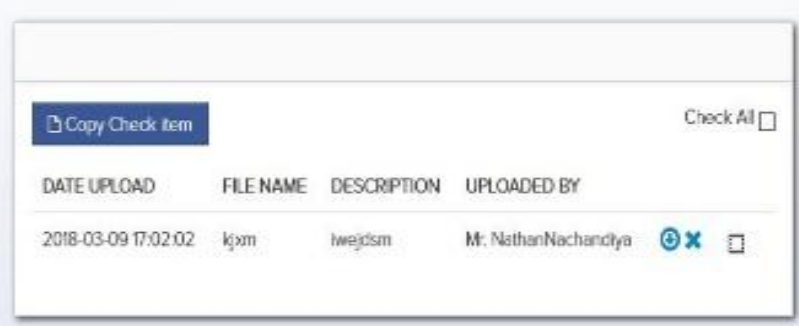

๑ Add Downloadable

P.

Ro ko sercod Clacosefwe

Filellat:

Descriotion

Fig 3. showing course materials upload.

\begin{tabular}{l}
\hline$\leftarrow \rightarrow$ C i $\quad$ (i) beatcstimsiteacher quizplp \\
Welcome to: ADSU LMS
\end{tabular}

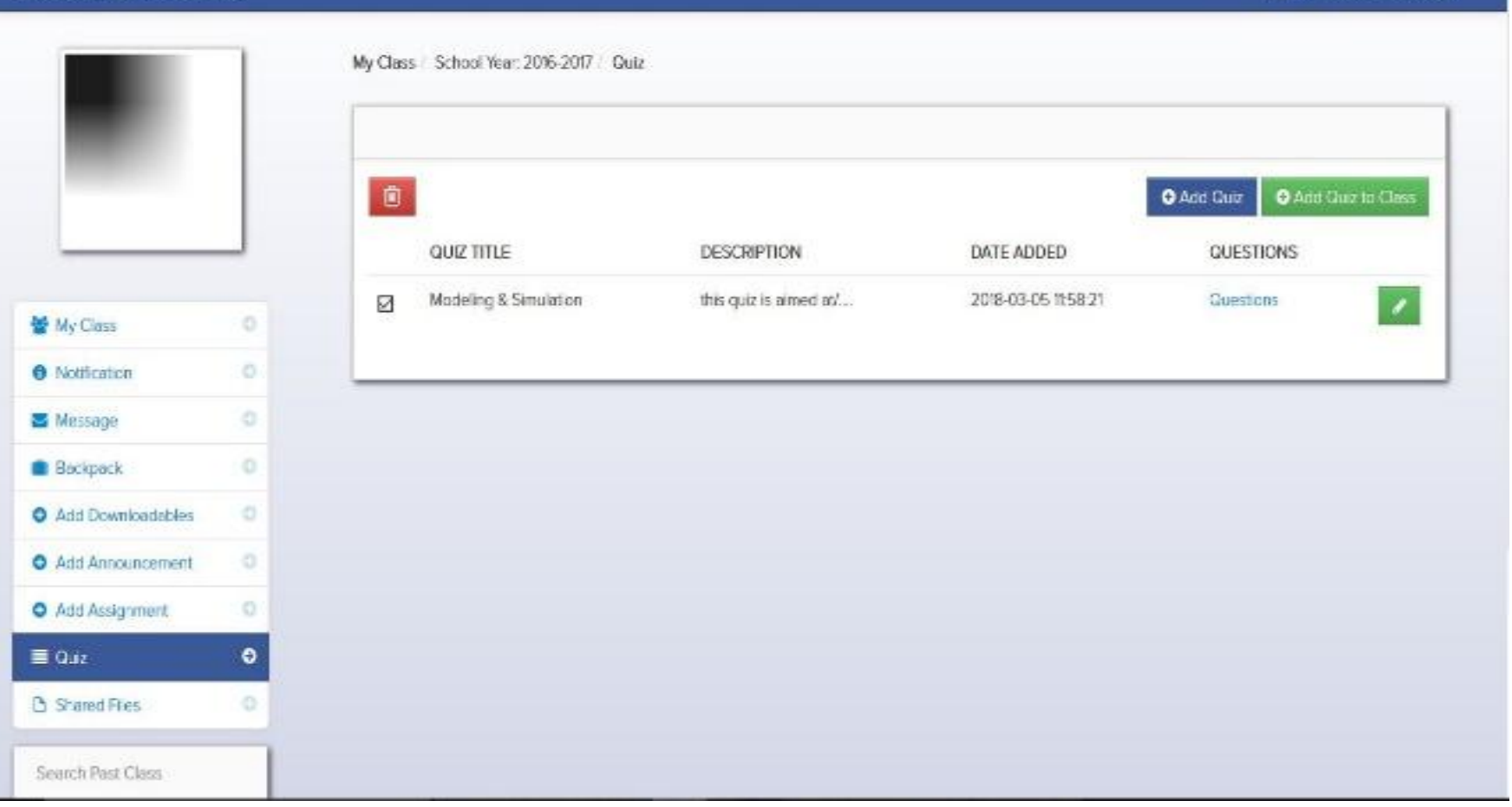

Fig 4. showing teacher adding quiz to class

\section{CONCLUSION}

LMS is a software that is best known for managing learning in higher institutions. This study gives insight of how LMS has been used and adopted by many educational institutions from around the world and Nigeria. Looking at the LMS developed, it is very clear that learners can benefit from it Based on the advantages it offers, LMS plays a vital role in learning administration and delivery based on its features; therefore, 
LMS adoption by Nigerian Institutions especially ADSU Mubi will give room for the utilization of such great technological advantages it offers through the use of the internet. Study also shows that staffs and students in various institutions has usability problems with the adoption of LMS, therefore, LMS that is to be developed has to be more userfriendly, with the enhancement of user-experience so as to enable them use the system effectively and without stress. This study however gives room for further improvement especially in terms of video content delivery.

\subsection{Recommendation}

Based on the implementation of the system, it is seen that there are some of the LMS features that has not been captured, therefore it is recommended that:

i. The system should support video content lessons so as to enable live streaming and video conferencing.

ii. Discussion forums should be integrated into the system so as to enable students to discuss matters that may arise in a class.

iii. It is also recommended that if possible, all institutions of higher learning especially in Nigeria should implement and adopt OLMS.

\subsection{Further Studies}

As a result of the increase in student numbers day by day in the education sector, or the need and importance to obtain knowledge whenever needed has made it necessary to use new technologies. Recently, LMSs has taken place at the front rows of the developing and changing technologies. This phase has already started in developed countries and is continuing to expand day by day. It is the researcher's opinion that, it is clear that if we wish to reach the levels of developed countries, we should start using the LMS systems as soon as possible especially in Nigerian higher institutions.

Moreover, some of the important features of LMS that has not been integrated into the system such as:

i. $\quad$ The video content delivery and

ii. Discussion forum

should be integrated for the improvement of the system so as to have a complete and robust LMS for flexible and excellent learning administration and delivery.

\section{REFERENCES}

[1] Aini, Z., Nur, S.A. (2016). Learning Management System of Higher Education Institution. Indian Journal of Science And Technology, Vol 9(9), DOI:10.17485/ijst/2016/v9i9/88717, November 2017.

[2] Andersson, A. \& Grönlund, Å., 2009. A conceptual framework for eLearning in developing countries: A critical review of research challenges. The Electronic Journal on Information Systems in Developing Countries, 38(8), pp.1-16.

[3] Bhalalusesa, R., Lukwaro, E.E. \& Clemence, M.(2013). Challenges of using elearning management systems faced by the academic staff in distance based institutions from developing countries: A case study of the Open University of Tanzania. Huria Journal of OUT, 14, pp.89-110.

[4] Bhatia, S. (2014). Learning Management System Trends. Training Magazine. Published by Lakewood Media Group, a LLC. Accessed November2017 at: http://www.trainingmag.com/learning-managementsystem-trends.

[5] Cavus, N., \& Momani, A. M. (2009). Computer aided evaluation of learning management systems. ProcediaSocial and Behavioural Sciences, 1(1), 426-430.

[6] Cavus, N. (2010). The evaluation of Learning Management Systems using an artificial intelligence fuzzy logic algorithm. Advances in Engineering Software, 41(2), 248-254.

[7] Curran, T. (2011). Open source or proprietary LMS? Your answer, my friend, is floating in the Cloud. In EdTech online. Accessed November 2017 at: http://tedcurran.net/2011/11/08/open-source-orproprietary-Ims-your-answer-my-friend-is-floating-inthe-cloud/

[8] Davis, B., Carmean, C., Wagner, E. D. (2009). The Evolution of the LMS: From Management to Learning. Deep Analysis of Trends Shaping the Future of eLearning. Sage Road Solutions LLC. The eLearning GuildTM, Santa Rosa, California, USA. Accessed November 2017

http://www.blackboard.com/resources/proed/guildImsreport.pdf

[9] Dube, S. \& Scott, E.( 2014). An empirical study on the use of the Sakai Learning Management System. In Proceedings of the e-Skills for Knowledge Production and Innovation Conference. Cape Town, South Africa, pp.101-107.

[10] Elmahadi, I. \& Osman, I. (2013). A study of the Sudanese students' use of collaborative tools within Moodle Learning Management System. In IST-Africa 2013 Conference Proceedings. pp.1-8.

[11] Eom, S.B. (2014). Understanding eLearners' satisfaction with Learning Management Systems. 16(2), pp.3-6.

[12] Ericsson, 2014. Sub-Saharan Africa Ericsson mobility report, Stockholm, Sweden. Available at: http://www.ericsson.com/res/docs/2014/emrjune2014-regional-appendices-ssa.pdf.

[13] Filippidi, A., Tselios, N. \& Komis, V., 2010. Impact of Moodle usage practices on students' performance in the context of a blended learning environment. In Social Applications for Lifelong Learning. Patra, Greece, pp. 16.

[14] Mayoka, K. \& Kyeyune, R. (2012). An analysis of eLearning Information System adoption in Ugandan Universities: Case of Makerere University Business School. Information Technology Research Journal, 2(1), pp.1-7.

[15] Mtebe, J.S. \& Raisamo, R. (2014). Investigating perceived barriers to the use of Open Educational Resources in higher education in Tanzania. International Review of Research in Open and Distance Learning, 15(2), 